2009-05

\title{
Numerical study of straight-bladed Darrieus-type tidal turbine
}

\author{
Dai, Yong Ming
}

http://hdl.handle.net/10026.1/3391

10.1680/ener.2009.162.2.67

Proceedings of the Institution of Civil Engineers, Energy

Thomas Telford

All content in PEARL is protected by copyright law. Author manuscripts are made available in accordance with publisher policies. Please cite only the published version using the details provided on the item record or document. In the absence of an open licence (e.g. Creative Commons), permissions for further reuse of content should be sought from the publisher or author. 


\section{PLYMOUTH UNIVERSITY}

\section{DEPOSIT LICENCE AGREEMENT FOR RESEARCH}

PEARL supports the long-term preservation of research outputs, and open access to them. To undertake this role, the administrators of PEARL need permission from authors to store, copy and migrate the material in order to ensure that it can be preserved and accessed in the future.

This Deposit License Agreement is designed to give PEARL administrators the right to do this, and to confirm that the author has the right to submit the material to the repository. The Licence Agreement is non-exclusive, and the depositor does not give away any of their rights to the repository.

\section{Depositor's declaration}

You (the Author) wish to deposit an electronic copy of the Work in the Plymouth University research repository (PEARL).

You agree that:

1. By accepting and submitting this license, you (the Author) grant Plymouth University the non-exclusive rights to reproduce, translate, migrate (as defined below), duplicate for back up processes and/or distribute your research (the Work), including the abstract, worldwide in print and electronic format and in any medium, including but not limited to audio or video.

2. The Author retains all rights in the Work in its present version or future versions. The research repository administrators or their agents may, without changing content, digitise and migrate the Work to any medium or format for the purpose of future preservation and accessibility. Plymouth University may keep more than one copy of this submission for purposes of security, back-up and preservation.

3. The Work deposited in the research repository (PEARL) will be accessible to individuals and institutions via the Internet subject to the terms and conditions granted in this agreement to Plymouth University and to the user of the research. Through the medium of the Internet, files will also be available to automated agents, and may be searched and copied by text mining and plagiarism detection software.

4. You are the Author and owner of the copyright in the Work and/or you have the authority of the author and owner of the copyright in the Work to make this agreement and grant Plymouth University a licence to make available the Work in digitised format through the research repository (PEARL) for the purposes of non-commercial research, private study, criticism, review and 
news reporting, illustration for teaching, and/or other educational purposes in electronic or print form

5. If your research does include any substantial subsidiary material for which you do not hold copyright, you have sought and obtained permission to make this third party material available to the public in digital format via a stand-alone device or a communications network and that this permission encompasses the rights that you have granted to Plymouth University. Any such third-party owned material should be clearly identified and acknowledged within the text or content of the submission

6. You have exercised reasonable care to ensure that the Work is original, and does not to the best of your knowledge break any UK law, infringe any third party's copyright or other Intellectual Property Right, or contain any confidential material.

7. If the Work is based upon research that has been sponsored or supported by an agency or organisation other than Plymouth University, or is covered by any publisher's agreement, you represent that you have fulfilled any right of review or other obligations required by such contract or agreement. Plymouth University shall retain the right to remove the Work for professional or administrative reasons, or if it is found to violate the legal rights of any person. Plymouth University will notify the depositor and the item will be removed from public view until the position is clarified.

8. Plymouth University does not have any obligation to take legal action on behalf of yourself, or other rights holders, in the event of infringement of intellectual property rights, breach of contract or of any other right, in the work.

\section{PEARL's rights and responsibilities:}

1. PEARL will clearly identify your name(s) as the author(s) or owner(s) of the submission, and will not make any alteration, other than as allowed by this license, to your submission.

2. PEARL undertakes not to distribute or translate this work for any commercial gain. The licence is required to allow deposit into PEARL and its successors. This licence may be passed to third party institutions (such as the British Library) if national or international policy advocates or requires a single repository of materials. Under no other condition will Plymouth University transfer the paper to others.

3. PEARL will ensure that the relevant metadata harvesting tools have access to the citation (including abstract) of the work to allow greater information discovery. 